\title{
Dexamethasone and Ketorolac as an adjuvant to Bupivacaine in axillary block for distal upper limb surgeries
}

\section{Raffat ahmed salem *; Haitham Mohamed Ali**;Fouad Ibraheam soliman***and Mohamed Hassan Abd elraouf*****}

\author{
*ass.Professor of Anesthesia \& Intensive Care ** Lecturer of anesthesia \\ $\& \mathrm{ICU} * * *$ Lecturer of anesthesia \& ICU **** M.B.Bch of Anesthesia \& \\ ICU
}

\begin{abstract}
Aim: To compare onset, duration and analgesic efficacy of axillary block when dexamethasone or ketorolac added to local anaethetic .

. Patient and Methods: 60 patients aged 18-65 years with ASA I-II who were candidate for distal upper limb surgeries by axillary nerve block were enrolled in this randomized controlled double blinded study, in sohag university hospital .

.Patients were Randomly allocated to( 3) groups (20) patients each ( using sealed envelope technique ) as :

- Dexamethasone (group D): patient received $30 \mathrm{ml}$ of 0.375 bupivacaine plus $8 \mathrm{mg}$ dexamethasone in $2 \mathrm{ml}$.

- ketorolac (group K):patient received $30 \mathrm{ml}$ of 0.375 bupivacaine plus $30 \mathrm{mg}$ ketorolac in $2 \mathrm{ml}$.

- control (group C) : patient received $30 \mathrm{ml}$ of 0.375 bupivacaine and normal saline 2ml).Immediately after administration; the patients were turned into the supine position. Patients were monitored for: Heart rate; NIBP and Oxygen Saturation. Patients were observed for onset, duration of sensory block and motor block; In the post-anesthesia care unit (PACU), the patients were asked to assess their level of pain based on a visual analog scale (VAS). Complications also were observed .Results: Dexamethasone had a faster Onset of sensory block onset than Magnesium Sulphate; Dexamethasone had a longer duration of regard Duration of motor block than Magnesium Sulphate; Magnesium Sulphate group had a longer analgesic effect stayed longer than Dexamethasone group .No Significant difference Between Two groups in rate of Complications ; Hypotension and Bradycardia were the most frequent complications in the two groups .Conclusion: The addition of dexamethasone to bupivacaine resulted in significant reduction in onset time of sensory and motor blocks, prolonged duration of post operative analgesia, lower analgesic consumption and lower incidence of complications
\end{abstract}

\section{Introduction:}

Regional anaethesia can reduce or avoid the hazards and discomfort of general anaethesia including sore throat, airway trauma, stress and difficulty of tracheal intubation and muscle pain, it also offers a number of advantages to outpatients under going surgery . these techniques provide prolonged postoperative analgesia and allow early patient's discharge. Regional anaethesia reduce the requirements of opioids reducing the incidence of postoperative nausea and 
vomiting . it can be used alone, in combination with sedation or as apart of balanced analgesia with general anaethesia (Rawal,2001).

Brachial plexus block is a popular and widely employed regional block technique for perioperative anesthesia and analgesia for surgeries of the upper extremity(Bridenbaugh, 1988).

An axillary brachial plexus nerve block is used frequently for forearm surgery . A peripheral nerve block has less of an effect on the cardiovascular and pulmonary systems and provide faster postoperative rehabilitation compared with general anaethesia, therefore it is preferable for some patients (Andersson A, Akeson J, Dahlin LB, 2006) .

Ultrasound guidance has improved the success and decreased the complication rate in regional anesthesia in general. The use of two-dimensional ultrasonic imaging to localize the brachial plexus has been highly successful in several approaches. The sonographic image can be used to guide the injection needle while minimizing the risk of injury of adjacent structures (Schwemmer et al 2006).

Recently various studies proved the efficacy of steroid like dexamethasone for its prolonging effects on the duration of regional nerve blocks. Dexamethasone is very potent and highly selective glucocorticoid. Basically it is used as anti-inflammatory and immunosuppressant . Clinical uses of dexametasone are for treatment of many inflammatory and autoimmune conditions but Glucocorticoids are also used to treat patients suffering from neuropathic pain and complex regional pain syndromes (CRPS) (Yadav, et al 2008

Steroid have nerve block prolonging effects by blocking transmission of nociceptive myelinated c-fibers and suppressing ectopic neuronal discharge. They are also thought to alter the function of potassium channels in the excitable cells( Pathak RG,et al 2012).

Ketorolac is a parenteral non-steroidal anti-inflammatry drug, which provide analgesia by inhibiting prostaglandin synthesis. It has been shown that ketorolac as an adjuvant to local anaethetics produces longer duration and better quality of analgesia during peripheral nerve block ( Reinhart DJ,et al 2000 ).

Patients and Methods

After approval of ethical committee , and written informed consent from 60 patients aged 18-65 years with ASA I-II who were candidate for distal upper limb surgeries by axillary nerve block were enrolled in this randomized controlled double blinded study, in sohag university hospital .

Exclusion criteria :

-Hypersensitivity to local anaethetic or additives .

- Local infection at site of injection .

- Patient with peripheral neuropathy .

- Coagulopathy .

- Patient refuse .

Patients were Randomly allocated to( 3 ) groups (20) patients each ( using sealed envelope technique ) as :

- Dexamethasone (group D): patient received $30 \mathrm{ml}$ of 0.375 bupivacaine plus $8 \mathrm{mg}$ dexamethasone in $2 \mathrm{ml}$.

- ketorolac (group K):patient received $30 \mathrm{ml}$ of 0.375 bupivacaine plus $30 \mathrm{mg}$ ketorolac in $2 \mathrm{ml}$.

- control (group C) : patient received 30 $\mathrm{ml}$ of 0.375 bupivacaine and normal saline $2 \mathrm{ml}$ After arrival to anaethetic room, IV line was inserted in the non operative upper limb and an infusion started with normal saline . supplemental oxygen ( $2 \mathrm{~L} /$ minute, by 
nasal cannula ) and routine anaethesia monitoring, including non invasive arterial blood pressure, heart rate ( ECG) and pulse oximetry was applied .Patient was premedicated with $1 \mathrm{mg}$ midazolam intravenously in the operating room before surgery started . The axillary brachial plexus block requires access to the axilla. Therefore abduction of the arm $90^{\circ}$ is an appropriate position that allows for transducer placement and needle advancement, as well as patient comfort - The pectoralis major muscle was palpated as it inserts onto the humerus, and the transducer $(10-\mathrm{MHz}$ linear transducer of A5 Sonoscape U/S , china ) was placed on the skin immediately distal to that point perpendicular to the axis of the arm

Once the artery was identified, an attempt was made to identify the hyperechoic median, ulnar, and radial nerves . Prescanning should also reveal the position of the musculocutaneous nerve, in the plane between the coracobrachialis and biceps muscles (a slight proximal-distal movement of the transducer is often required to bring this nerve into view) .

A 22-gauge spinal needle ( Braun, Quincke, by Malaysia) was inserted inplane from the cephalad aspect and directed toward the posterior aspect of the axillary artery .

This technique involves the injection of $2 \mathrm{~mL}$, which 'peels apart' the plane in which the needle tip was continuously inserted. The needle was then advanced a few millimeters and more injectate is administered .

Local anesthetic should be deposited posterior to the artery first, to avoid displacing the structures of interest deeper and obscuring the nerves, which is often the case if the median or ulnar nerves are injected first. Once $10 \mathrm{~mL}$ was administered, the needle was withdrawn almost to the level of the skin, redirected toward the median and ulnar nerves, and a further $15 \mathrm{~mL}$ is injected in these areas to complete the circle around the artery.

Finally, the needle was once again withdrawn and redirected toward the musculocutaneous nerve. Once adjacent to the nerve, $5 \mathrm{~mL}$ of local anesthetic is deposited .

The following parameters will be assisted after institution of the blockade. Onset and duration of sensory block

- Onset and duration of motor block

- Duration of post operative analgesia and total consumption of analgesics

- Side effects and complications if present

Modified Bromage Scale (3Point scale) Grade $0=$ normal motor function with full flexion\ extention of elbow, wrist and fingers .

Grade 1 = decreased motor strength with ability to move fingers andlor wrist only .

Grade 2 = complete motor blockade with inability to move fingers . 


\section{Results:}

\begin{tabular}{|c|c|c|c|}
\hline $\begin{array}{l}\text { Onset } \\
\text { of } \\
\text { sensory } \\
\text { block }\end{array}$ & $\begin{array}{l}\text { Controls } \\
\mathrm{N}=\mathbf{2 0}\end{array}$ & $\begin{array}{l}\text { Dexamethasone } \\
\mathrm{N}=\mathbf{2 0}\end{array}$ & $\begin{array}{l}\text { Ketorolac } \\
\mathbf{N}=\mathbf{2 0}\end{array}$ \\
\hline $\begin{array}{l}\text { Mean } \pm \\
\text { SD } \\
\text { Median } \\
\text { (range) }\end{array}$ & $\begin{array}{l}18.9 \pm 3.2 \\
18 \quad(14- \\
25)\end{array}$ & $\begin{array}{l}15.1 \pm 3.5 \\
15(10-20)\end{array}$ & $\begin{array}{l}17.3 \pm 3.6 \\
17(10-24)\end{array}$ \\
\hline \multicolumn{4}{|c|}{ P compared 3 group $=0.004 *$} \\
\hline \multicolumn{4}{|c|}{$\begin{array}{l}\mathrm{P} \text { compared controls and dexamethasone }=0.003 * \\
\mathrm{P} \text { compared controls and ketorolac }=0.44\end{array}$} \\
\hline \multicolumn{4}{|c|}{ P compared dexamethasone and ketorolac $=0.15$} \\
\hline
\end{tabular}

Table shows Onset of sensory block of studied populations

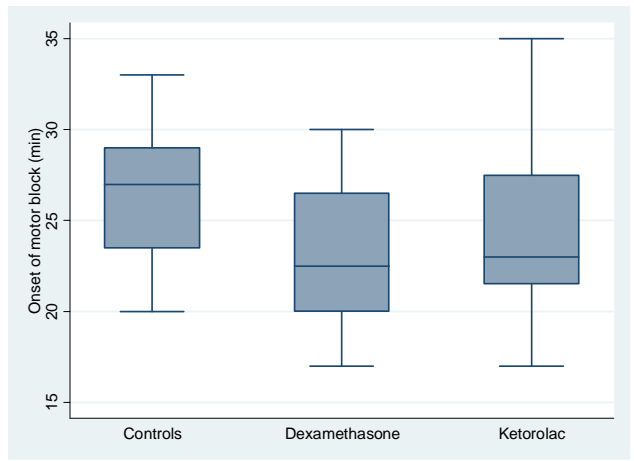

Figure shows Onset of motor block of studied populations

\begin{tabular}{|l|l|l|l|}
\hline $\begin{array}{l}\text { Time of } \\
\text { first } \\
\text { analgesia }\end{array}$ & $\begin{array}{l}\text { Controls } \\
\mathrm{N}=20\end{array}$ & $\begin{array}{l}\text { Dexamethasone } \\
\mathrm{N}=20\end{array}$ & $\begin{array}{l}\text { Ketorolac } \\
\mathrm{N}=20\end{array}$ \\
\hline $\begin{array}{l}\text { Mean } \pm \\
\text { SD }\end{array}$ & $\begin{array}{l}382.9 \pm 53.6 \\
\text { Median } \\
\text { (range) }\end{array}$ & $\begin{array}{l}674(303.7 \pm 9- \\
586(430-787)\end{array}$ & $\begin{array}{l}576.6 \pm 93.7 \\
553.5 \\
(410-745)\end{array}$ \\
\hline P compared 3 group $<0.0001 \quad *$ \\
\hline \multicolumn{2}{|l|}{ P compared controls and dexamethasone $<0.0001 \quad *$} \\
\hline \multicolumn{2}{|l|}{ P compared controls and ketorolac <0.0001 * } \\
\hline \multicolumn{2}{|l|}{ P compared dexamethasone and ketorolac $=0.90$} \\
\hline
\end{tabular}

Table shows Time of first analgesia of studied populations

Satistical analysis:

Data was analyzed using STATA intercooled version 12.1. Quantitative data was represented as mean, standard deviation, median and range. Data was analyzed using ANOVA for comparison of the means of three groups. When the data was not normally distributed Kruskal Wallis test was used. Qualitative data was presented as number and percentage and compared using Chi square test. Graphs were produced by using Excel or STATA program. P value was considered significant if it was less than 0.05 . 


\section{Discussion:}

This study showed that ,The addition of dexamethasone to bupivacaine resulted in significant reduction in onset time of sensory and motor blocks, prolonged duration of post operative analgesia, lower analgesic consumption and lower incidence of complications.

his study showed that, there was statistically significant difference between the 3 groups as regard mean onset of sensory block as it was $(18.9 \pm 3.2)$ minutes in controls, (15.1 \pm 3.5$)$ minutes in Dexamethasone group, and (17.3 \pm 3.6$)$ minutes in Ketorolac group with $\mathrm{p}$ value 0.004 also ; there was statistically significant difference between controls and dexamethasone with $\mathrm{p}$ value 0.003 while there was no statistically significant difference between controls and ketorolac groups and between dexamethasone and ketorolac groups with non significant $p$ value .

This study showed that, there was statistically significant difference between the 3 groups as regard Mean onset of motor block as it was (26.6 \pm 3.8$)$ minutes in controls, $(22.9 \pm 4.2)$ minutes in Dexamethasone group, and $(24.1 \pm 4.6)$ minutes in Ketorolac group with $\mathrm{p}$ value 0.02 also ; there was statistically significant difference between controls and dexamethasone with $\mathrm{p}$ value 0.02 . This mean that onset of sensory and motor block was more rapid in Dexamethasone group compared to other two groups while there was no statistically significant difference between controls and ketorolac groups and between dexamethasone and ketorolac groups with non significant $p$ value .

This study showed that, there was statistically significant difference between the 3 groups as regard Mean duration of sensory block as it was $(303.5 \pm 43.1)$ minutes in controls, $(440.2 \pm 59.4)$ minutes in Dexamethasone group, and (398.2 \pm 66.3$)$ minutes in Ketorolac group with $\mathrm{p}$ value $<0.0001$ also ; there was statistically significant difference between controls and dexamethasone with $\mathrm{p}$ value $<0.0001$ and there was significant statistically difference between controls and ketorolac with $\mathrm{p}$ value $<0.0001$, while there was no statistically significant difference between dexamethasone and ketorolac groups with non significant $p$ value .

This study showed that, there was statistically significant difference between the 3 groups as regard Mean duration of motor block was $(255.7 \pm 43.6)$ minutes in controls, $(384.8 \pm 56.14) \quad$ minutes in Dexamethasone group, and (336.2 \pm 64.1$)$ minutes in Ketorolac group with $\mathrm{p}$ value $<0.0001$ also ; there was statistically significant difference between controls and dexamethasone with $\mathrm{p}$ value <0.0001 and there was significant statistically difference between controls and ketorolac with $\mathrm{p}$ value $<0.0001$ and there statistically significant difference between dexamethasone and ketorolac with $\mathrm{p}$ value 0.02 .

This study showed that, there was statistically significant difference between the 3 groups as regard Mean Time of first analgesia ( duration of analgesia ) was $(382.9 \pm 53.6)$ minutes in controls, $(603.7 \pm 92.0)$ minutes in Dexamethasone group, and (576.6 \pm 93.7$)$ minutes in Ketorolac group with $\mathrm{p}$ value $<0.0001$ also ; there was statistically significant difference between controls and dexamethasone 
with $\mathrm{p}$ value $<0.0001$ and there was statistically significant difference between controls and ketorolac with $\mathrm{p}$ value $<0.0001$ while there was no statistically significant difference between dexamethasone and ketorolac Conclusion:

The addition of dexamethasone to bupivacaine resulted in significant reduction in onset time of sensory and motor blocks, prolonged duration of post operative analgesia, lower analgesic consumption and lower incidence of complications.

The use of ultrasound helped us in good localization of brachial plexus and prevented occurrence of major complications.

\section{References:}

1- Abdallah FW, Johnson J, Chan V, et al. Intravenous dexamethasone and perineural dexamethasone similarly prolong the duration of analgesia after supraclavicular brachial plexus block: a randomized, triple arm, double-blind placebo-controlled trial. Regional Anesthesia and Pain Medicine 2015;40: 125-32.

2- Anand LK, JindalR (2009).Regional anaesthesia for upper extremity in orthopaedics:areview article.Punjab J,Orthopaedics 11:1-8.

3- Anderson A Akeson j, Dahlin LB, Efficacy and safety of axillary block for operations on hand, scand j plast Reconstr Surg Hand Surg . 2006:40:225-229.

4- Arish B T, Dinesh Babu D, Suneeth $P$ Lazarus, D Dilip Chandar, S Balasubramanian, K Suresh Kumar. Effect of Dexamethasone as an Adjuvant to Local Anesthetic in Supraclavicular Brachial Plexus Block.

5- Borgeat A,Ekatodramis G,Schenker CA.Postoperative nausea and vomiting inregional anesthesia :a eview. Anesthesiology.2003;98:530-47. groups with non significant $\mathrm{p}$ value . This mean that duration of sensory and motor block was longer in Dexamethasone group compared to other two groups.

6- Choi S, Rodseth R, McCartney CJ. Effects of dexamethasone as a local anaesthetic adjuvant for brachial plexus block: A systematic review and meta-analysis of randomized trials. Br J Anaesth 2014;112:113.

7- Choi S, Rodseth R, McCartney CJL. Effects of dexamethasone as a local anaesthetic adjuvant for brachial plexus block: a systematic review and meta-analysis of randomized trials. Br J Anaesth. 2014.1-13.

8- Chung KC, Spilson SV. The frequency and epidemiology of hand and forearm fractures in the United States. JHand Surg Am2001; 26: 908-915.

9- Cummings KC 3rd, Napierkowski DE, Parra-Sanchez I, Kurz A, Dalton JE, Brems $\mathrm{JJ}$, et al. Effect of dexamethasone on the duration of interscalene nerve blocks with ropivacaine or bupivacaine. $\mathrm{Br} \mathrm{J}$ Anaesth 2011;107:446-53.

10- Desmet M, Braems H, Renvoet M, et al. I.V. and perineural dexamethasone are equivalent in increasing the analgesic duration of a single shot interscalene block with ropivacaine for shoulder surgery: a prospective, randomized, placebocontrolled study. British Journal of Anaesthesia 2013; 111: 445-52. Doi:0.17354/ijss/2016/29.

11- Duma A, Urbanek B, Sitzwohl C, Kreiger A, Zimpfer M, Kapral S. Clonidine as an adjuvant to local anaesthetic axillary brachial plexus block: A randomized, controlled study. Br

Anaesth. 2005;94:112-6. 
12- International Journal of Scientific Study | January 2016 | Vol 3 | Issue 10.

Karl Sa Ribeiro, Anjali Ollapally, Julie Misquith. Dexamethasone as an Adjuvant to Bupivacaine in Supraclavicular Brachial Plexus Block in Paediatrics for Postoperative Analgesia. Journal of Clinical and Diagnostic Research. 2016 Dec, Vol10(12): UC01-UC04

13- Movafegh A, Razazian M, Hajimaohamadi F, Meysamie A. Dexamethasone added to lidocaine prolongs axillary brachial plexus blockade. Anesth Analg 2006;102:263-7 
